\title{
Combination therapy of inhaled steroids and long-acting beta2-agonists in asthma-COPD overlap syndrome
}

This article was published in the following Dove Press journal:

International Journal of COPD

8 November 2016

Number of times this article has been viewed

\begin{abstract}
Suh-Young Lee, ${ }^{1, *}$ Hye Yun Park, ${ }^{2, *}$ Eun Kyung Kim, ${ }^{3}$ Seong Yong Lim, ${ }^{4}$ Chin Kook Rhee, ${ }^{5}$ Yong II Hwang, ${ }^{6}$ YeonMok Oh, ${ }^{7}$ Sang Do Lee, ${ }^{7}$ Yong Bum Park'
\end{abstract}

On behalf of the KOLD Study Group

'Division of Pulmonary, Allergy, and Critical Care Medicine, Department of Internal Medicine, Kangdong Sacred Heart Hospital, Hallym University College of Medicine, ${ }^{2}$ Division of Pulmonary and Critical Care Medicine, Department of Medicine, Samsung Medical Center, Sungkyunkwan University School of Medicine, Seoul, ${ }^{3}$ Department of Internal Medicine, Bundang CHA Medical Center, CHA University College of Medicine, Seongnam, ${ }^{4}$ Department of Medicine, Kangbuk Samsung Hospital, Sungkyunkwan University School of Medicine, ${ }^{5}$ Division of Pulmonology and Critical Care Medicine, Department of Internal Medicine, Seoul St Mary's Hospital, College of Medicine, The Catholic University of Korea, Seoul, ${ }^{6}$ Division of Pulmonary, Allergy and Critical Care Medicine, Department of Medicine, Hallym University Sacred Heart Hospital, Hallym University Medical School, Gyeonggido, 'Department of Pulmonary and Critical Care Medicine, Asan Medical Center, University of Ulsan College of Medicine, Ulsan, Republic of Korea

*These authors contributed equally to this work

Correspondence: Yong Bum Park Division of Pulmonary, Allergy, and Critical Care Medicine, Department of Internal Medicine, Kangdong Sacred Heart Hospital, Hallym University College of Medicine, 150, Seongan-ro, Gangdong-gu, Seoul, I34-70I, South Korea

Tel +82 222242754

Fax +82 222242569

Email bfspark2@gmail.com
Background: The efficacy of inhaled corticosteroids (ICSs)/long-acting beta2-agonist (LABA) treatment in patients with asthma-chronic obstructive pulmonary disease (COPD) overlap syndrome (ACOS) compared to patients with COPD alone has rarely been examined. This study aimed to evaluate the clinical efficacy for the improvement of lung function after ICS/LABA treatment in patients with ACOS compared to COPD alone patients.

Methods: Patients with stable COPD were selected from the Korean Obstructive Lung Disease (KOLD) cohort. Subjects began a 3-month ICS/LABA treatment after a washout period. ACOS was defined when the patients had 1) a personal history of asthma, irrespective of age, and wheezing in the last 12 months in a self-reported survey and 2) a positive bronchodilator response.

Results: Among 152 eligible COPD patients, 45 (29.6\%) fulfilled the criteria for ACOS. After a 3-month treatment with ICS/LABA, the increase in forced expiratory volume in 1 second $\left(\mathrm{FEV}_{1}\right)$ was significantly greater in ACOS patients than in those with COPD alone $(240.2 \pm 33.5$ vs $124.6 \pm 19.8 \mathrm{~mL}, P=0.002)$. This increase in $\mathrm{FEV}_{1}$ persisted even after adjustment for confounding factors (adjusted $P=0.002$ ). According to severity of baseline $\mathrm{FEV}_{1}$, the ACOS group showed a significantly greater increase in $\mathrm{FEV}_{1}$ than the COPD-alone group in patients with mild-to-moderate airflow limitation $(223.2 \pm 42.9$ vs $84.6 \pm 25.3 \mathrm{~mL}, P=0.005)$, whereas there was no statistically significant difference in patients with severe to very severe airflow limitation. Conclusion: This study provides clinical evidence that ACOS patients with mild-to-moderate airflow limitation showed a greater response in lung function after 3 months of ICS/LABA combination treatment.

Keywords: pulmonary disease, chronic obstructive, asthma, respiratory function tests

\section{Introduction}

Chronic obstructive pulmonary disease (COPD) and asthma are two major pulmonary diseases characterized by chronic airway inflammation; the features of both the diseases are often shared in substantial patients who present with chronic respiratory symptoms and airflow limitation. Recently, the disease entity of asthma-COPD overlap syndrome (ACOS) has been described and identified by global guidelines, ${ }^{1,2}$ and $13 \%-55 \%$ of COPD patients are estimated to have characteristics of ACOS depending on the diagnostic criteria applied..$^{3-5}$ Despite inconsistent ACOS diagnosis criteria or definition, numerous studies have consistently reported that patients with ACOS experience more respiratory symptoms, severe and frequent exacerbations, comorbidities, and healthcare utilization compared to those with COPD alone. ${ }^{6-8}$

Treatment in ACOS patients is poorly implemented because pharmacological clinical trials have excluded either asthma patients from COPD studies or COPD patients from 
asthma studies. ${ }^{9}$ The key difference in treatment between the two diseases is the use of inhaled corticosteroids (ICSs). ICS is the principal treatment of choice for asthma, while its usage is recommended only for those COPD patients with severeto-very severe airflow limitation and frequent exacerbations that are not adequately controlled by long-acting bronchodilators, according to current guidelines. ${ }^{1}$ Recently, patients with ACOS have been suggested to be more responsive to ICS compared to those with COPD alone; ${ }^{10}$ however, the benefits of ICS has rarely been examined in patients with ACOS.

In the current guidelines, long-acting beta2-agonist (LABA) monotherapy is considered as first-line therapy in COPD patients, but LABA monotherapy without ICS is never considered to be acceptable in asthma patients. ${ }^{2}$ In addition, ICS monotherapy is not recommended in COPD patients. ${ }^{1}$ Thus, this study aimed to evaluate the clinical efficacy for lung function improvement after a 3-month combined inhalation of ICS and a long-acting $\beta 2$-agonist (LABA) in ACOS patients compared with those with COPD alone.

\section{Methods}

\section{Subjects}

This study retrospectively analyzed data from patients with stable COPD selected from the Korean Obstructive Lung Disease (KOLD) cohort, which is prospectively recruited from the pulmonary clinics of 14 hospitals in South Korea between June 2005 and December 2012. ${ }^{11}$ The criteria for COPD patients to be enrolled in KOLD are as follows: age $\geq 40$ years, presence of airflow limitation that was not fully reversible (post-bronchodilator forced expiratory volume in 1 second/forced vital capacity $\left[\mathrm{FEV}_{1} / \mathrm{FVC}\right]<70 \%$ ), smoking history $>10$ pack-years, and no or minimal abnormality on chest radiography. After enrollment in the KOLD cohort, some subjects underwent a 2-week washout period and then received treatment including a fixed-dose combination inhaler of ICS and LABA. However, subjects whose condition did not allow cessation of medications did not undergo a washout period and maintained their original treatment. This decision was made at the discretion of the treating physicians. Baseline clinical data including Charlson comorbidity score, extent of dyspnea (modified Medical Research Council [mMRC] dyspnea score), blood eosinophil count, lung function, and chest CT scan were obtained after cessation of the following respiratory medications: an ICS for 2 weeks, an inhaled LABA or long-acting muscarinic antagonist for 2 days, and an inhaled short-acting $\beta 2$-agonist or inhaled short-acting anticholinergic for 12 hours. Spirometry and lung volumes were again measured following the 3-month treatment. Subjects who underwent a washout period were treated with a fixed-dose combination inhaler of ICS and LABA (50 $\mu \mathrm{g}$ salmeterol/500 $\mu \mathrm{g}$ fluticasone or $9 \mu \mathrm{g}$ formoterol $/ 320 \mu \mathrm{g}$ budesonide, twice daily) for the following 3 months after the washout period. After exclusion of 30 subjects using tiotropium in addition to ICS and LABA during the 3 months, a total of 152 subjects remained eligible for this study. The institutional review boards of all participating hospitals (Ajou Institutional Review Board; Asan Medical Center Institutional Review Board; CHA Bundang Medical Center, CHA University Institutional Review Board; Ewha Womans University Mokdong Hospital Institutional Review Board; Hanyang University Guri Hospital Institutional Review Board; Inje University Ilsan Paik Hospital Institutional Review Board; Kangbuk Samsung Hospital Institutional Review Board; Kangnam Sacred Heart Hospital Institutional Review Board; Kangwon National University Hospital Institutional Review Board; Korea University Anam Hospital Institutional Review Board; National Medical Center Institutional Review Board; Seoul National University Bundang Hospital Institutional Review Board; Seoul National University Hospital Institutional Review Board; Yeouido St Mary’s Hospital, Institutional Review Board) approved the study protocol, and written informed consent was obtained from all the patients.

\section{Pulmonary function tests}

Spirometry was performed using a Vmax 22 instrument (Sensor-Medics; Yorba Linda, CA, USA) or a PFDX machine (MedGraphics, St Paul, MN, USA), as recommended by the American Thoracic Society/European Respiratory Society. ${ }^{12}$ $\mathrm{FVC}, \mathrm{FEV}_{1}$, and $\mathrm{FEV}_{1} / \mathrm{FVC}$ were evaluated both before and $15 \mathrm{~min}$ after inhalation of $400 \mu \mathrm{g}$ albuterol. Lung volume was measured by body plethysmography (V600, SensorMedics, or PFDX). $\mathrm{DL}_{\mathrm{CO}}$ was assessed by the single-breath method using a Vmax229D (Sensor-Medics) or a Masterlab Body (Jaeger AB, Wurtsburg, Germany) instrument. Absolute values of FVC and $\mathrm{FEV}_{1}$ were obtained, and the percentage of the predicted value (\% predicted) for $\mathrm{FEV}_{1}$ and $\mathrm{FVC}$ was calculated from equations formulated using data from a population of healthy non-smoking Koreans. ${ }^{13}$ Spirometry was conducted at baseline and after 12 weeks of treatment.

\section{Computed tomography (CT)}

Volumetric CT scans were performed using 16-slice multidetector CT scanners as previously described. ${ }^{14}$ The extent of emphysema (emphysema index) was estimated using the threshold technique quantifying the percentage ratio of low attenuation areas (an apparent X-ray attenuation value below $-950 \mathrm{HU}$ ) to the corresponding lung areas. ${ }^{15}$ Airway wall areas were measured near the origin of the right apical 
and left apico-posterior segmental bronchi as selected by the consensus of two radiologists. ${ }^{16}$

\section{Definition of ACOS, the severity of airflow limitation, and $F E V$, responders}

ACOS was defined when patients had 1) a personal history of asthma irrespective of age and wheezing in the last 12 months in a self-reported survey and 2) a positive bronchodilator response defined as a $>12 \%$ and $200 \mathrm{~mL}$ post-bronchodilator increase in $\mathrm{FEV}_{1}$ from baseline values. ${ }^{8} \mathrm{COPD}$ severity was classified according to the Global Initiative for Chronic Obstructive Lung Disease (GOLD) grading system: mildto-moderate, $\mathrm{FEV}_{1} \geq 50 \%$ predicted; and severe to very severe, $\mathrm{FEV}_{1}<50 \%$ predicted. ${ }^{1}$ Subjects were classified as $\mathrm{FEV}_{1}$ responders or $\mathrm{FEV}_{1}$ non-responders based on an $\mathrm{FEV}_{1}$ improvement of at least $12 \%$ and $200 \mathrm{~mL}$ from baseline after 3 months of combined treatment with ICS/LABA. ${ }^{17}$

\section{Statistical analysis}

The baseline characteristic data are presented as mean \pm standard deviation if normally distributed or as median (interquartile range [IQR]) if non-normally distributed for continuous variables as appropriate. Categorical variables were presented as frequency with percentage. Continuous variables were analyzed using a $t$-test or Mann-Whitney $U$-test based on normality, and categorical data were compared using Pearson's $\chi^{2}$ test or Fisher's exact test. A multiple linear regression for $\mathrm{FEV}_{1}$ changes following a 3-month ICS/LABA treatment, and a logistic regression analysis for $\mathrm{FEV}_{1}$ responders were performed with adjustment for the following variables: Model 1 contained demographic variables of age (continuous), body mass index (BMI, continuous), and smoking pack-years; Model 2 additionally included pulmonary-related variables of baseline $\mathrm{FEV}_{1}$, baseline mMRC, baseline CT-determined emphysema index, and peripheral blood eosinophils ( $\geq 260 / \mu \mathrm{L}$ ). ${ }^{17}$ Sex was excluded as a covariate because $97.4 \%$ of the population was male. We used the Hosmer-Lemeshow test to verify the goodness of the model fit. A two-sided $P$-value $<0.05$ was considered significant. All statistical tests were performed using SPSS Statistics, version 22.0 (IBM, Armonk, NY, USA).

\section{Results}

\section{Patient characteristics}

As shown in Table 1, 45 subjects (29.6\%) fulfilled the definition of ACOS. There were no significant differences in age, sex, BMI, smoking history, initial Charlson comorbidity score, and dyspnea score (mMRC) between the ACOS and COPD-alone

Table I Baseline characteristics of ACOS and COPD-alone patients

\begin{tabular}{|c|c|c|c|}
\hline & $\operatorname{ACOS}(\mathrm{N}=45)$ & COPD alone $(N=107)$ & $P$-value \\
\hline Age, years & $64(6 I-70)$ & $68(6 I-7 I)$ & 0.440 \\
\hline Male (n) & $44(97.8)$ & $104(97.2)$ & 1.000 \\
\hline Body mass index, $\mathrm{kg} / \mathrm{m}^{2}$ & $23.9(22.3-25.6)$ & $23.1(20.4-25.4)$ & $0.13 \mid$ \\
\hline \multicolumn{4}{|l|}{ Smoking status } \\
\hline Current smoker & $17(37.8)$ & $44(4 I . I)$ & 0.721 \\
\hline Pack-years & $44.0(36.6-55.0)$ & $45.0(30.0-55.0)$ & 0.729 \\
\hline Charlson comorbidity score & $1.0(1.0-1.0)$ & $1.0(1.0-1.0)$ & 0.684 \\
\hline mMRC dyspnea score & $1.0(1.0-2.0)$ & $1.0(1.0-2.0)$ & 0.366 \\
\hline \multicolumn{4}{|l|}{ Severity of airflow limitation } \\
\hline Severe to very severe & $17(37.8)$ & $38(35.5)$ & 0.854 \\
\hline \multicolumn{4}{|l|}{ Pulmonary function test } \\
\hline FVC, L' & $3.34(2.62-3.66)$ & $3.25(2.65-3.87)$ & 0.715 \\
\hline FVC, \% predicted & $82.0(73.2-95.5)$ & $87.0(73.0-99.0)$ & 0.323 \\
\hline $\mathrm{FEV}_{\text {, }} \mathrm{L}$ & $1.53(1.19-1.81)$ & $1.52(1.09-1.91)$ & 0.569 \\
\hline $\mathrm{FEV}_{1}, \%$ predicted & $54.9(44.5-65.5)$ & $56.0(43.0-72.0)$ & 0.339 \\
\hline TLC, L & $6.17(5.62-7.11)$ & $6.78(5.63-7.48)$ & 0.319 \\
\hline $\mathrm{RV}, \mathrm{L}$ & $3.03(2.4|-3.5|)$ & $2.93(2.15-4.00)$ & 0.192 \\
\hline IC, L & $2.05(1.67-2.39)$ & $1.92(1.56-2.52)$ & 0.718 \\
\hline $\mathrm{DL}_{\mathrm{CO}}, \%$ & $85.0(66.0-96.0)$ & $83.0(71.0-101.3)$ & 0.848 \\
\hline \multicolumn{4}{|l|}{ CT determined } \\
\hline Emphysema index, \% & $15.6(7.6-27.0)$ & I 5.7 (7.3-33.5) & 0.240 \\
\hline Mean wall area, $\%$ & $66.5(62.4-70.2)$ & $65.7(62.0-69.4)$ & 0.545 \\
\hline \multicolumn{4}{|l|}{ Peripheral eosinophil count } \\
\hline Eosinophil count, $/ \mu \mathrm{L}$ & $213.3(134.2-339.5)$ & $197.1(108.3-360.4)$ & 0.251 \\
\hline Eosinophil count $\geq 260, \%$ & $20(44.4)$ & $43(40.2)$ & 0.719 \\
\hline
\end{tabular}

Note: The data are presented as number (\%) or as median and interquartile range.

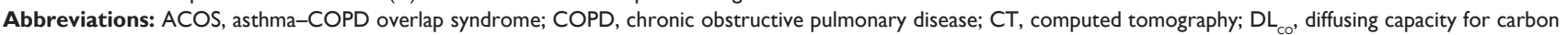
monoxide; $\mathrm{FEV}_{1}$, forced expiratory volume in I second; FVC, forced vital capacity; IC, inspiratory capacity; mMRC, modified Medical Research Council; RV, residual volume; TLC, total lung capacity. 
Table 2 Changes of pulmonary function and symptom score, and the rate of acute exacerbation after 3 months of treatment in $\mathrm{ACOS}$ and COPD-alone patients

\begin{tabular}{clll}
\hline & $\begin{array}{l}\text { ACOS } \\
(\mathbf{N}=\mathbf{4 5})\end{array}$ & $\begin{array}{l}\text { COPD alone } \\
(\mathbf{N}=\mathbf{l 0 7})\end{array}$ & P-value \\
\hline Changes of pulmonary function and symptom score & \\
$\Delta \mathrm{FEV}, \mathrm{mL}$ & $240.2 \pm 33.5$ & $124.6 \pm 19.8$ & 0.002 \\
$\Delta \mathrm{FVC}, \mathrm{mL}$ & $304.8 \pm 59.0$ & $150.2 \pm 38.1$ & 0.030 \\
$\Delta \mathrm{TLC}, \mathrm{mL}$ & $435.3 \pm 264.0$ & $888.3 \pm 247.7$ & 0.213 \\
$\Delta \mathrm{RV}, \mathrm{mL}$ & $-93.3 \pm 156.0$ & $102.8 \pm 129.5$ & 0.380 \\
$\Delta \mathrm{IC}, \mathrm{mL}$ & $166.9 \pm 84.9$ & $141.5 \pm 62.6$ & 0.820 \\
$\Delta \mathrm{mMRC}$ & $-0.05 \pm 0.17$ & $-0.39 \pm 0.08$ & 0.126 \\
Acute exacerbation, \% & 15.0 & 12.2 & 0.719 \\
\hline
\end{tabular}

Note: The baseline PFT data are presented as median and interquartile range, and lung function changes are presented as mean \pm standard error.

Abbreviations: ACOS, asthma-COPD overlap syndrome; COPD, chronic obstructive pulmonary disease; $\mathrm{FEV}_{1}$, forced expiratory volume in I second; FVC, forced vital capacity; IC, inspiratory capacity; mMRC, modified Medical Research Council; RV, residual volume; TLC, total lung capacity.

groups. In addition, 37.8\% (17/45) of the ACOS group and $35.5 \%$ (38/107) of the COPD-alone patients had severe to very severe airflow limitation. Initial $\mathrm{FEV}_{1}, \mathrm{FVC}$, total lung capacity (TLC), residual volume (RV), inspiratory capacity (IC), $\mathrm{DL}_{\mathrm{CO}}$, CT-determined emphysema index, and mean wall area were not different between the two groups. Blood eosinophil count was $213.3 / \mu \mathrm{L}$ (IQR, 134.2-339.5/ $\mu \mathrm{L}$ ) in the ACOS group and 197.6/ $\mu \mathrm{L}$ (IQR, 113.2-364.0/ $\mu \mathrm{L}$ ) in the COPD-alone group, which were not significantly different.

\section{Changes of pulmonary function and symptom score} following 3 months of ICS/LABA treatment

The changes of TLC, RV, and IC during the 3 months were not different between the ACOS and COPD-alone groups, while $\mathrm{FEV}_{1}(240.2 \pm 33.5$ vs $124.6 \pm 19.8 \mathrm{~mL}, P=0.002)$ and FVC (304.8 \pm 59.0 vs $150.2 \pm 38.1 \mathrm{~mL}, P=0.030)$ significantly increased with 3 months of ICS/LBA treatment in the ACOS group compared with the COPD-alone group (Table 2). The change of mMRC score and the rate of acute exacerbations during 3 months did not show significant differences between ACOS and COPD-alone groups (Table 2). When comparing $\mathrm{FEV}_{1}$ increase based on the severity of airflow limitation, the ACOS group showed greater improvement than the COPD-alone group in patients with mild-to-moderate airflow limitation ( $223.2 \pm 42.9$ vs $84.6 \pm 25.3 \mathrm{~mL}, P=0.005)$, but the $\mathrm{FEV}_{1}$ increase did not reach statistical significance in those with severe to very severe airflow limitation $(268.2 \pm 54.5$ vs 197.1 $\pm 28.4 \mathrm{~mL}, P=0.209)$ (Figure 1A). The percentage of $\mathrm{FEV}_{1}$ responders was also higher in the ACOS group than the COPD-alone group in patients with mild-to-moderate airflow limitation ( $46.4 \%$ vs $12.7 \%, P=0.025)$ but not in those with severe to very severe airway obstruction $(70.6 \%$ vs $44.6 \%$ $P=0.089$; Figure 1B).

\section{ACOS as a predictor of FEV increase following 3 months of ICS/LABA treatment}

The presence of ACOS was independently associated with $\mathrm{FEV}_{1}(\mathrm{~mL})$ increase $(P=0.002)$ and $\mathrm{FEV}_{1}$ responders $(P=0.003)$, which persisted even after adjustment for age, BMI, smoking history, initial mMRC dyspnea score, initial $\mathrm{FEV}_{1}$, emphysema index, and high eosinophil count $(>260 / \mu \mathrm{L})\left(\mathrm{FEV}_{1}[\mathrm{~mL}]\right.$ increased [adjusted $\left.P=0.012\right]$ and $\mathrm{FEV}_{1}$ responders [adjusted $P=0.006$, model 2]; Figure 2). In addition, model 2 showed that age (adjusted $P=0.009$ and adjusted $P=0.006$ ), baseline $\mathrm{FEV}_{1}$ (adjusted $P=0.002$ and adjusted $P=0.003)$, and blood eosinophil count $>260 / \mu \mathrm{L}$ (adjusted $P=0.034$ and adjusted $P=0.004$ ) were correlated with both $\mathrm{FEV}_{1}(\mathrm{~mL})$ increase and $\mathrm{FEV}_{1}$ responders (Table S1).
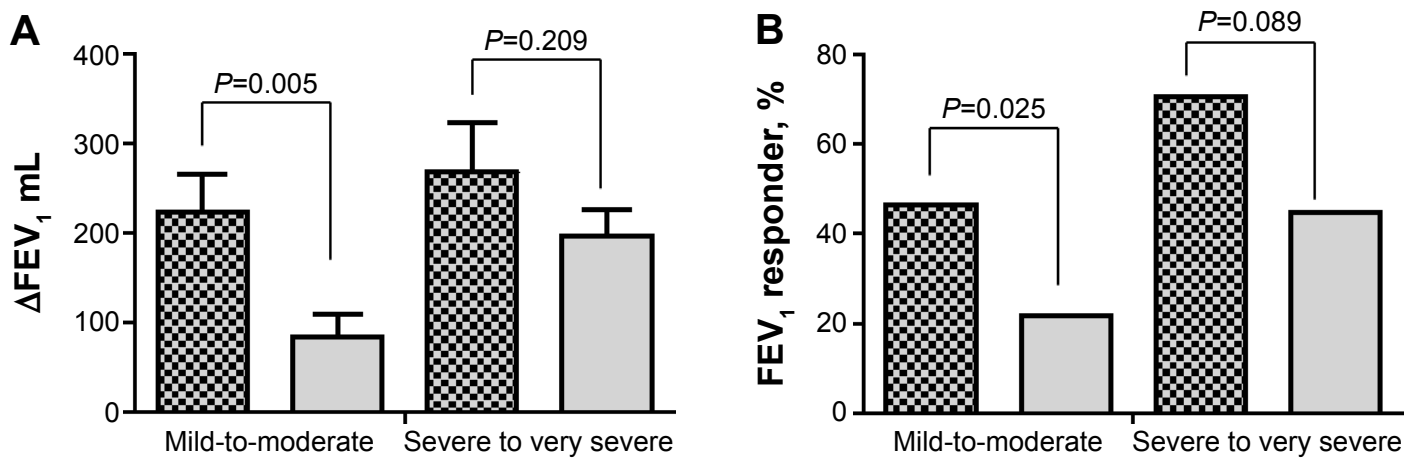

ACOS $\square$ COPD alone

Figure I Comparison of change in FEV, between ACOS and COPD-alone patients.

Note: The ACOS group showed a significantly greater increase in FEV, than the COPD-alone group in patients with mild-to-moderate airflow limitation but not in patients with severe to very severe airflow limitation. (A) $\triangle \mathrm{FEV},(\mathrm{mL})$; (B) $\mathrm{FEV}_{\text {, }}$ responders (\%).

Abbreviations: ACOS, asthma-COPD overlap syndrome; COPD, chronic obstructive pulmonary disease; FEV , forced expiratory volume in I second. 

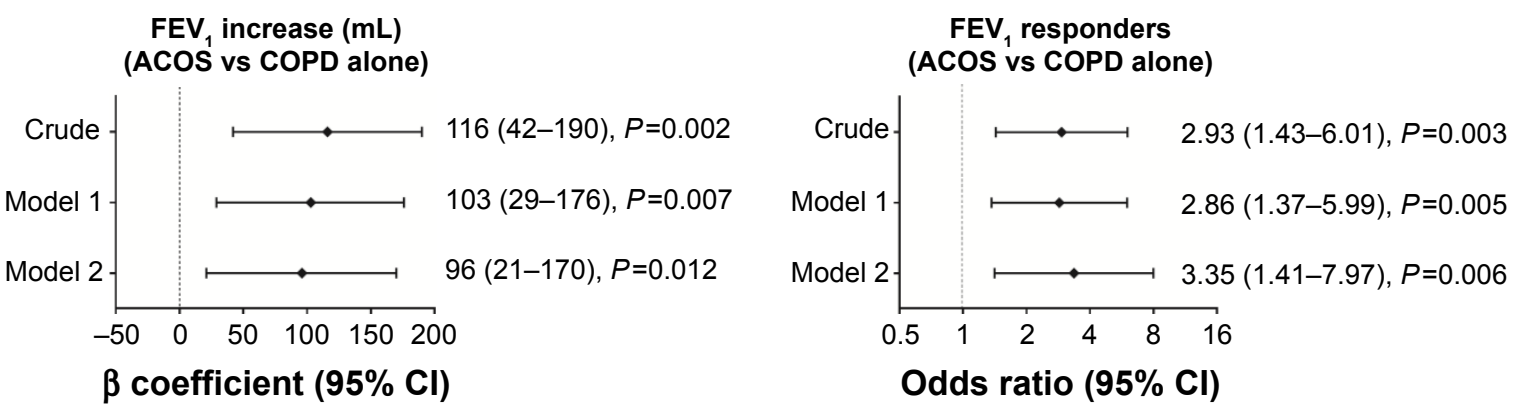

Figure 2 Independent associations of ACOS with FEV, increase and FEV, responders.

Note: The presence of ACOS was independently associated with $\mathrm{FEV}$, increase and $\mathrm{FEV}$, responders compared with COPD alone.

Abbreviations: ACOS, asthma-COPD overlap syndrome; $\mathrm{Cl}$, confidence interval; COPD, chronic obstructive pulmonary disease; FEV , forced expiratory volume in I second.

\section{Discussion}

In the present study, it was found that the $\mathrm{FEV}_{1}$ increment following 3 months of ICS/LABA treatment was significantly higher in the ACOS group compared with COPD-alone group, which persisted after adjustment for baseline characteristics, baseline $\mathrm{FEV}_{1}$, emphysema index, and eosinophil count. Moreover, the difference in $\mathrm{FEV}_{1}$ increment was definite in patients with mild-to-moderate airflow limitation.

Contrary to treatment for asthma, the beneficial effects of ICS treatment for COPD have been debated. ICS reduces the risk of exacerbations, ${ }^{18,19}$ but the effect of ICS monotherapy is weaker in improving lung function than that of long-acting bronchodilators, and it does not affect mortality or the rate of decline in lung function. ${ }^{20-22}$ Moreover, long-term high-dose exposure to ICS increases the risk of pneumonia. ${ }^{23}$ On the basis of clinical trials, current guidelines recommend ICS not as monotherapy but as a combination with long-acting bronchodilators in patients with severe airflow limitation and frequent exacerbations, despite regular bronchodilator treatment. ${ }^{1}$ However, in real clinical practice, ICSs are widely used in combination with long-acting bronchodilators, even in COPD patients with mild-to-moderate airflow limitation. ${ }^{24,25}$ This discrepancy with current guidelines requires the identification of features associated with ICS responsiveness in COPD patients. The present study showed a significant increase in $\mathrm{FEV}_{1}$ following 3 months of treatment with ICS/LABA in the ACOS group compared with COPD alone, especially in those with the mild-to-moderate airflow limitation. In addition, due to various modifications in defining ACOS, this study also analyzed the data with other ACOS criteria ${ }^{9}$ proposed by experts (replaced "documented history of asthma before 40 years of age" with "history of asthma" due to absence of age at diagnosis) and found still significant increase in $\mathrm{FEV}_{1}$ following 3 months of treatment with ICS/LABA in the new defined ACOS group (Figure S1).
Previous studies have shown that patients with ACOS are younger, more likely to be female, and have more symptoms and poorer health status than those with COPD alone; ;, ,26 however, these observations could not be reproduced. This might be explained by the predominantly male patients in the study population, due to a high smoking prevalence and medical service utilization by men in Korea, ${ }^{27,28}$ and another reason is that the recruitment of patients was mostly from secondary and tertiary hospitals, who often had more symptoms than those from primary clinics. Regarding eosinophils, previous studies have reported a higher eosinophil count in the sputum of patients with ACOS than in that of those with COPD alone,$^{10}$ and sputum eosinophilia is considered as a predictor of clinical benefits of ICS in COPD. ${ }^{10,29,30}$ Although the previous ${ }^{17}$ and present studies showed that high eosinophil blood count was a significant predictor of increase in $\mathrm{FEV}_{1}$ following a 3-month ICS/LABA treatment, eosinophil blood count per se, was not different between patients with ACOS and COPD alone, which is consistent with data from ECLIPSE. ${ }^{26}$

This study had some limitations. First, it focused on lung function improvement following 3 months of ICS/LABA treatment between ACOS and COPD-alone groups. Further studies with long-term clinical outcomes such as lung function decline, exacerbations, and mortality are necessary. Second, all patients enrolled in this study received ICS/ LABA combination therapy; thus, the single effects of ICS or LABA could not be compared. Third, personal history of asthma irrespective of age was based on patient recall, which might have under- or overestimated the proportion of asthma patients in this study. To reduce recall bias, a history of wheezing in the last 12 months and bronchodilator response to the ACOS criteria was added.

In conclusion, this study showed that ICS/LABA treatment is more effective for $\mathrm{FEV}_{1}$ improvement in patients with ACOS than in those with COPD alone, which was significant in patients with mild-to-moderate airflow limitation. 


\section{Acknowledgments}

This KOLD Study was supported by the grant from the Korea Healthcare Technology R\&D Project, Ministry of Health and Welfare (HI10C2020 and A102065). This study was supported by Samsung Medical Center Foundation for Medical Research (SMX1151371).

\section{Disclosure}

The authors report no conflicts of interest in this work.

\section{References}

1. Global Initiative for Chronic Obstructive Lung Disease. Global Strategy for the Diagnosis, Management, and Prevention of Chronic Obstructive Pulmonary Disease (Updated 2016). Available from: http://www. goldcopd.org. Accessed August 1, 2016.

2. Global Initiative for Asthma. Global Strategy for Asthma Management and Prevention (Updated 2016). Available from: http://ginasthma.org/. Accessed August 1, 2016.

3. Marsh SE, Travers J, Weatherall M, et al. Proportional classifications of COPD phenotypes. Thorax. 2008;63(9):761-767.

4. Hardin M, Silverman EK, Barr RG, et al. The clinical features of the overlap between COPD and asthma. Respir Res. 2011;12:127.

5. Gibson PG, McDonald VM. Asthma-COPD overlap 2015: now we are six. Thorax. 2015;70(7):683-691.

6. Miravitlles M, Soriano JB, Ancochea J, et al. Characterisation of the overlap COPD-asthma phenotype. Focus on physical activity and health status. Respir Med. 2013;107(7):1053-1060.

7. Hardin M, Cho M, McDonald ML, et al. The clinical and genetic features of COPD-asthma overlap syndrome. Eur Respir J. 2014;44(2): 341-350.

8. Menezes AM, Montes de Oca M, Perez-Padilla R, et al. Increased risk of exacerbation and hospitalization in subjects with an overlap phenotype: COPD-asthma. Chest. 2014;145(2):297-304.

9. Sin DD, Miravitlles M, Mannino DM, et al. What is asthma-COPD overlap syndrome? Towards a consensus definition from a round table discussion. Eur Respir J. 2016;48(3):664-673.

10. Kitaguchi Y, Komatsu Y, Fujimoto K, Hanaoka M, Kubo K. Sputum eosinophilia can predict responsiveness to inhaled corticosteroid treatment in patients with overlap syndrome of COPD and asthma. Int $J$ Chron Obstruct Pulmon Dis. 2012;7:283-289.

11. Park TS, Lee JS, Seo JB, et al. Study design and outcomes of Korean Obstructive Lung Disease (KOLD) Cohort Study. Tuberc Respir Dis (Seoul). 2014;76(4):169-174.

12. Miller MR, Hankinson J, Brusasco V, et al. Standardisation of spirometry. Eur Respir J. 2005;26(2):319-338.

13. Cho JK, Paek DY, Lee JO. Normal predicted values of spirometry in Korean population. Tuberc Respir Dis. 2005;58:230-242.

14. Oh YM, Jeong BH, Woo SY, et al. Association of plasma adipokines with chronic obstructive pulmonary disease severity and progression. Ann Am Thorac Soc. 2015;12(7):1005-1012.
15. Gevenois PA, de Maertelaer V, De Vuyst P, Zanen J, Yernault JC. Comparison of computed density and macroscopic morphometry in pulmonary emphysema. Am J Respir Crit Care Med. 1995;152(2):653-657.

16. Lee JS, Huh JW, Chae EJ, et al. Different therapeutic responses in chronic obstructive pulmonary disease subgroups. Int J Tuberc Lung Dis. 2011;15(8):1104-1110.

17. Park HY, Lee H, Koh WJ, et al. Association of blood eosinophils and plasma periostin with FEV1 response after 3-month inhaled corticosteroid and long-acting beta2-agonist treatment in stable COPD patients. Int J Chron Obstruct Pulmon Dis. 2016;11:23-30.

18. Gartlehner G, Hansen RA, Carson SS, Lohr KN. Efficacy and safety of inhaled corticosteroids in patients with COPD: a systematic review and meta-analysis of health outcomes. Ann Fam Med. 2006;4(3): 253-262.

19. Jones PW, Willits LR, Burge PS, Calverley PM. Disease severity and the effect of fluticasone propionate on chronic obstructive pulmonary disease exacerbations. Eur Respir J. 2003;21(1):68-73.

20. Burge PS, Calverley PM, Jones PW, Spencer S, Anderson JA, Maslen TK. Randomised, double blind, placebo controlled study of fluticasone propionate in patients with moderate to severe chronic obstructive pulmonary disease: the ISOLDE trial. BMJ. 2000;320(7245):1297-1303.

21. Lung Health Study Research Group. Effect of inhaled triamcinolone on the decline in pulmonary function in chronic obstructive pulmonary disease. N Engl J Med. 2000;343(26):1902-1909.

22. Vestbo J, Sorensen T, Lange P, Brix A, Torre P, Viskum K. Longterm effect of inhaled budesonide in mild and moderate chronic obstructive pulmonary disease: a randomised controlled trial. Lancet. 1999;353(9167):1819-1823.

23. Kew KM, Seniukovich A. Inhaled steroids and risk of pneumonia for chronic obstructive pulmonary disease. Cochrane Database Syst Rev. 2014;3:CD010115

24. Price D, West D, Brusselle G, et al. Management of COPD in the UK primary-care setting: an analysis of real-life prescribing patterns. Int $J$ Chron Obstruct Pulmon Dis. 2014;9:889-904.

25. Vestbo J, Vogelmeier C, Small M, Higgins V. Understanding the GOLD 2011 Strategy as applied to a real-world COPD population. Respir Med. 2014;108(5):729-736.

26. Wurst KE, Rheault TR, Edwards L, Tal-Singer R, Agusti A, Vestbo J. A comparison of COPD patients with and without ACOS in the ECLIPSE study. Eur Respir J. 2016;47(5):1559-1562.

27. Yoo KH. Smoking cessation and chronic obstructive pulmonary disease. Korean J Intern Med. 2015;30(2):163-166.

28. Rhee CK, Yoon HK, Yoo KH, et al. Medical utilization and cost in patients with overlap syndrome of chronic obstructive pulmonary disease and asthma. COPD. 2014;11(2):163-170.

29. Leigh R, Pizzichini MM, Morris MM, Maltais F, Hargreave FE, Pizzichini E. Stable COPD: predicting benefit from high-dose inhaled corticosteroid treatment. Eur Respir J. 2006;27(5):964-971.

30. Brightling CE, McKenna S, Hargadon B, et al. Sputum eosinophilia and the short term response to inhaled mometasone in chronic obstructive pulmonary disease. Thorax. 2005;60(3):193-198. 


\section{Supplementary materials}

Table SI Multiple logistic regression analysis of clinical factors associated with FEV $(\mathrm{mL})$ change after 3 months of ICS/LABA treatment

\begin{tabular}{|c|c|c|c|c|c|c|}
\hline \multirow[t]{2}{*}{ Variables } & \multicolumn{3}{|c|}{ FEV $_{1}(\mathrm{~mL})$ change } & \multicolumn{3}{|c|}{ FEV, responder* } \\
\hline & $\beta$ coefficient & $95 \% \mathrm{Cl}$ & $P$-value & OR & $95 \% \mathrm{Cl}$ & $P$-value \\
\hline ACOS & 95.82 & $21.383-170.258$ & 0.012 & 3.352 & I.409-7.972 & 0.006 \\
\hline Age & -6.232 & $-10.894-1.570$ & 0.009 & 0.921 & $0.868-0.977$ & 0.006 \\
\hline BMI & 11.680 & $0.380-22.979$ & 0.043 & 1.033 & $0.908-1.176$ & 0.621 \\
\hline Smoking status, pack-years & -0.226 & $-1.707-1.256$ & 0.764 & 0.995 & $0.977-1.013$ & 0.605 \\
\hline $\mathrm{mMRC}$ & 24.973 & $-10.49 \mid-60.437$ & 0.166 & 1.217 & $0.798-1.857$ & 0.362 \\
\hline Baseline FEV, & -122.788 & $-198.469-47.107$ & 0.002 & 0.223 & $0.083-0.600$ & 0.003 \\
\hline Emphysema index on CT & -3.607 & $-6.257-0.957$ & 0.008 & 0.979 & $0.948-1.010$ & 0.177 \\
\hline Blood eosinophil count $>260 / L$ & 72.931 & $5.758-140.103$ & 0.034 & 3.292 & I.476-7.346 & 0.004 \\
\hline
\end{tabular}

Note: *Defined by an $\mathrm{FEV}$, improvement of at least $12 \%$ and $200 \mathrm{~mL}$ from baseline after 3 months of combined treatment with ICS/LABA.

Abbreviations: ACOS, asthma-COPD overlap syndrome; BMI, body mass index; $\mathrm{Cl}$, confidence interval; COPD, chronic obstructive pulmonary disease; $\mathrm{CT}$, computed tomography; ICS, inhaled corticosteroid; FEV ${ }_{1}$, forced expiratory volume in I second; LABA, long-acting beta2-agonist; mMRC, modified Medical Research Council; OR, odds ratio.

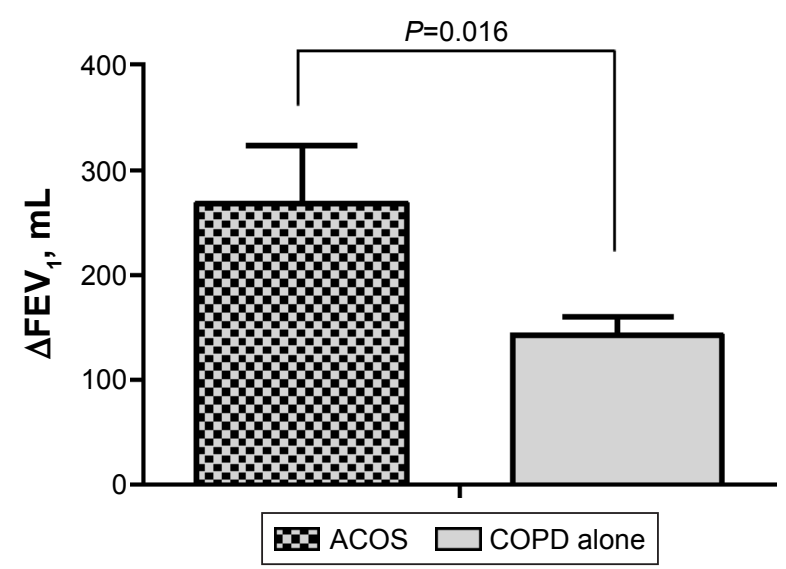

Figure SI Comparison of change in $\mathrm{FEV}_{1}(\mathrm{~mL})$ between $\mathrm{ACOS}$ and COPD-alone patients.

Note: ACOS patients, classified with other criteria' proposed by experts, showed a significantly greater increase in FEV than those with COPD alone.

Abbreviations: ACOS, asthma-COPD overlap syndrome; COPD, chronic obstructive pulmonary disease; FEV , forced expiratory volume in I second.

\section{Reference}

1. Sin DD, Miravitlles M, Mannino DM, et al. What is asthma-COPD overlap syndrome? Towards a consensus definition from a round table discussion. Eur Respir J. 2016;48(3):664-673.

\section{Publish your work in this journal}

The International Journal of COPD is an international, peer-reviewed journal of therapeutics and pharmacology focusing on concise rapid reporting of clinical studies and reviews in COPD. Special focus is given to the pathophysiological processes underlying the disease, intervention programs, patient focused education, and self management protocols.

\section{Dovepress}

This journal is indexed on PubMed Central, MedLine and CAS. The manuscript management system is completely online and includes a very quick and fair peer-review system, which is all easy to use. Visit http://www.dovepress.com/testimonials.php to read real quotes from published authors. 